\title{
Self-Reported Learning from Co-Teaching Primary Science Lessons to Peers at University
}

\author{
Peter Hudson $^{1}$, Shaun Nykvist ${ }^{2}$, \& Michelle Mukherjee ${ }^{3}$
}

\begin{abstract}
Universities are challenged continuously in reviews to improve teacher education, which includes providing substantial theory-practice connections for undergraduates. This study investigated secondyear preservice teachers' $(n=48)$ self-reported learning as a result of co-teaching primary science to their peers within the university setting. From extended written responses and observations of teaching practice, data indicated learning around the following themes: lesson implementation, content knowledge, teaching strategies, confidence to teach, questioning skills, grade appropriateness of content, time management, and how to critically observe co-teaching. The co-teaching episodes within the university setting were emphasised as a way to build confidence and as development of plausible science lessons for implementation in authentic primary classrooms. Co-teaching primary science to peers scaffolds the development of teaching skills and practices through dual roles as both teachers and student recipients.
\end{abstract}

Keywords: Praxis, preservice teachers, theory and practice, co-teaching

\section{Introduction}

Education reform is ongoing. For years, in the United States (American Association for the Advancement of Science, 1990), United Kingdom (Lunn \& Solomon, 2000), and Australia (Goodrum, Hackling, \& Rennie, 2001) reform has highlighted the need to improve science education, and this continues in Australia (Masters, 2009). One focus of reform is on preservice teacher development with recommendations to increase the connection between theory and practice (i.e., praxis). Numerous educators (e.g.,Cochran-Smith\&Zeichner, 2007; Korthagen, 2001) have provided strong arguments and evidence on how to enhance praxis, that is, by challenging preservice teachers todevelop content knowledge and pedagogical knowledge through practical applications. Yet,praxis generally involves preservice teachers entering schools. This study focuses on preservice teachers' self-reported learning as a result of teaching primary sciencein the university setting.

\section{Literature review}

Teaching is complicated and complex. However, there appears to beparticular pedagogical knowledge practices that can lead towards effective teaching (Hudson, 2004), which will be discussed in the following literature review. Effective teaching involves devising plans that are linked to relevant curriculum documents and provide a structure for delivering lessons (Rush, Blair, Chapman, Codner, \& Pearce, 2008). To be purposeful in learning, these plans must target specific curriculum standards (Davis, Petish, \& Smithey, 2006). To plan effectively the teacher needs to have knowledge of the content matter, students, and

\footnotetext{
${ }^{1}$ Southern Cross University

${ }^{2}$ Queensland University of Technology

${ }^{3}$ Queensland University of Technology
} 
curriculum standards. Such planning requires long and short-term goals where "the teacher must understand and be able to effectively use multiple methods of formal and informal assessment" (Davis et al., 2006, p. 622). Part of the plan is timetabling lessons to ensure the plans are appropriately scheduled (Williams, 1993). There is evidence to suggest that the time of day for certain lessons can affect school performance (Randler\&Frech, 2009), which may change from subject to subject and year level to year level.Another contributing factor to learning is the amount of instructional time allocated for subjects, for which there needs to be more research around optimal instructional durations (e.g., Corey, Phelps, Ball, Demonte, \&Harrison, 2012).

Preparation for teaching includes plans and extends to setting up teaching and learning resources (Rosaen\& Lindquist, 1992; Youens\& McCarthy, 2007). Importantly, the teacher needs to prepare for, and demonstrate, appropriate content knowledge for teaching (e.g., Burn, 2007; Cleaves \&Toplis, 2008; Youens\& McCarthy, 2007). This subject knowledge must relate to students' needs and their levels of development (Harris \& Sass, 2009). A teacher's command of content knowledge appears to have a positive effect on student learning in addition to teachers reporting that "inquiry instructionalstrategies contributed to improvement in their students' achievement" (Buczynski\& Hansen, 2010, p. 604). Nevertheless, it should be noted that content knowledge alone isby no means the only factor indicative of good teaching (Pantić\&Wobbels, 2010). Explicit teaching "is achieved by knowledgeable,committed teachers who tailor and adapt their practices to theongoing needs of all of the students in their classes" (Parr \&Limbrick, 2010, p. 584).

Other pedagogical knowledge practices such as selecting and applying appropriate teaching strategies can play a key role for implementing successful lessons (Jeanpierre, 2007; Lappan\& Briars, 1995). For instance, in one study (Bradfield \& Hudson, 2012), preservice teachers note teaching strategies used for differentiating learning include: (1) understanding contexts for learning, (2) designating facilitators for students' learning, including teacher, peers, parents, and support staff such as teachers aides, (3) managing student groups, and (4) utilising a range of teaching aids (visual, auditory, games) and resources.

Problems and issues can arise during lessons that require problem solving (Ackley \& Gall, 1992), which Schön (1987) identifies as reflection in practice. These problems and issues can range from inadequate preparation, including lack of resources, to managing student behaviour.Indeed, a main consideration for teaching is classroom management, and in particular behaviour management (Feiman-Nemser\& Parker, 1992; McKinney, CampbellWhately, \& Kea, 2005), where a teacher's skills can be challenged (Maag, 2008; O'Brien \& Goddard, 2006).So it is not surprising that preservice teachers would grapple with behaviour management in their early stages of development (Putman, 2009). Woodcock's (2010) study shows that preserviceteachers use "lowlevelorinitialcorrectivestrategieswhen addressingbehaviouralissues" and further indicate that the use of "bothpreventionandlowlevelcorrective strategiestobeequallysuccessful when dealingwithstudentbehaviour" ( $p$. 1266). As might be expected, the study also shows that preservice teachers use strategies where they feel most confident in employing such strategies. There is little doubt that "preservice teachers need to master skills of managing classroom to prevent frustration when they confront with the realities of classroom life", which requires "the development of a strong sense of efficacy and competent management strategies" (Gencer\&Cakiroglu, 2007, p. $672)$. 
Implementation of the lesson structure with cognisance of timeframes can assist the flow of an activity (Briscoe \& Peters, 1997; Jeanpierre, 2007). Implementation demonstrates not only an introduction, body and conclusion to the lesson but that "lessons had an arrived at learning aim that was clearlyarticulated, shared with the students and demonstrably understoodby the students" (Parr \&Limbrick, 2010, p. 589). Effective implementation of a lesson necessitates explicitteaching and a process of scaffolding and monitoring students' learning. During the implementation stage, teachers ask students questions pitched at the student's zone of proximal development (e.g., Jeanpierre, 2007). Such questioning can also assist with diagnostic, formative and summative assessments.

Assessment must be planned and embedded in the lesson activities to determine students' learning as a result of the lesson (Corcoran \& Andrew, 1988; Tillema, 2009). Assessments can involve the teacher, student as a learner, and peers (Ozogul, Olina, \& Sullivan, 2008). Research (Kohler, Henning, \&Usma-Wilches, 2008) shows that preservice teachers generally use observations of students' performances as formativeassessment strategies yet other methods "such as examining writing or products, administering tests or quizzes, or having students engage in selfassessment" are rarely accomplished (p. 2114). Finally, there can be viewpoints about effective teaching that may help to guide pedagogical practices (e.g., Jonson, 2002; McKinney et al., 2005; Tillema, 2009). These viewpoints are generally representedthrough the teacher's philosophy of teaching, which materialises from beliefs about what constitutes effective teaching and learning. This current study aimed to explore preservice teachers' self-reported learning for co-teaching a primary science lesson to their peers.

The rationale for teaching primary science to peers is formed around two assumptions, articulated by Santagata, Zannoni, and Stigler (2007) as: "(1) exposure to examples of teaching creates learning opportunities for prospective teachers; and (2) through field experiences preservice teachers meld theory into practice" (p. 124). The field experience in this study involves co-teaching to peers, which also aligns with Bandura's (1986) vicarious experiences as recipients of peers' co-teaching and development of mastery experiences as co-presenters of primary science lessons. Presenting primary science lessons to peers was intended to demonstrate different teaching practices, which provided contexts for analysing what works and what does not work. The research question was: Whatdo preservice teachers' report about their learningwhen co-teaching primary science lessons to peers in the university setting?

\section{Context}

There were 188 second-year preservice teachers involved in a nine-week primary science university unit at one Australian university. The unit encompassed a one hour lecture, one hour tutorial and two hour workshop.Tutorials were formed around devising a primary science unit of work and the workshops provided hands-on experiences with the addition of the preservice teachers presenting science lessons to their peers. Various online resources were available to the preservice teachers including ideas for primary lessons, lesson plan formats, and links to state and national websites outlining key curriculum documents (e.g., http://www.australiancurriculum.edu.au/Science/Curriculum/F-10). During the nine weeks, lectures and tutorials covered the following topics: (1) science in society and working with primary students; (2) rationalising a science unit with theories and approaches; (3) devising a science curriculum; (4) planning science lessons and the importance of content knowledge and pedagogical knowledge (Hudson, 2004); (5) managing the learning environment; (6) resources 
for teaching primary science; (7) assessment and evaluation in science education (Hudson, 2007a); (8) curriculum integration (Hudson, 2012); and (9) High Impact Teaching Strategies (HITS; see Hudson, 2007b).

The workshops required pairs of preservice teachers to co-teach a 45-minute primary science lesson by adhering to the following criteria:

- Model a sound and timely lesson structure including a stimulating introduction, engaging student-centred activities, and purposeful conclusion linked to the key scientific concepts.

- Demonstrate constructivist principles with prior knowledge, use of questioning, handson/minds-on activities while facilitating active and inclusive student participation.

- Present effective teaching strategies including preparation, planning, and appropriate classroom management.

- Show a clear understanding of the content knowledge associated with your teaching topic (introduction, astute questioning, and key concept development).

- Employ teaching and learning technologies effectively to cater for the range of student abilities within the timeframe (e.g., early finishers, inclusivity).

- Demonstrate professionalism and collaborative team teaching with an understanding of the affective domain for teaching and learning (e.g., enthusiasm, confidence, and attitude).

- Linklesson material to syllabus documents with a variety of resources, including relevant websites.

- Provide a thoughtful and thorough health and safety form.

Apart from drawing on the pedagogical knowledge indicated in the literature review, Figure 1 provided a model for planning their science lessons and further highlighted the relationship between assessment, evaluation and other lesson components. For instance, the outcome or standard will be derived from the current presiding curriculum, in this case the Australian Curriculum: Science (ACARA, 2012). The selection of a key scientific concept was designed to provide the students stronger focus on the content knowledge appropriate for the "primary students". The hands-on activitiesneeded to be connected to health and safety requirements, lesson duration, resources, and the teaching strategies to facilitate student learning. The activities also included pedagogical knowledge of teaching practices such as classroom management, questioning, and lesson implementation design (e.g., see Hudson, 2012). Figure 1 shows what can be assessed and evaluated, and guided their written critical self reflection, which was to be submitted individually for assessment a week after the peer presentation. At the conclusion of the peer presentation, the presenters elicited feedback from their peers using a self-designed one-page survey with written responses. This allowed the preservice teachers to specifically target their areas of need and facilitated ownership of their learning. The tutor also provided brief and confidential verbal feedback, where most presenters took notes so they could combine with peer feedback towards writing their critical self reflection on their lesson presentation. 


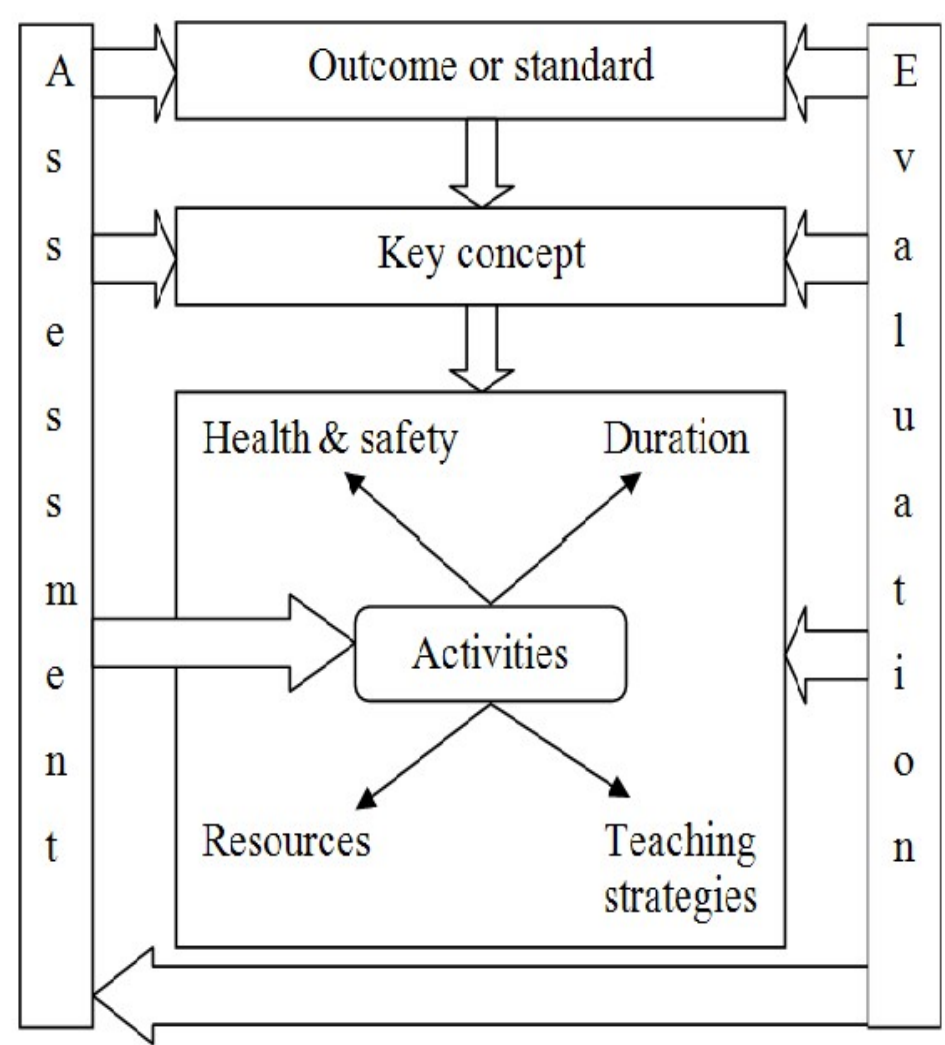

Figure 1: Model for planning, assessing and evaluating a science lesson

\section{Data collection methods and analysis}

From a pool of 188 second-year preservice teachers involved in a primary science unit, this study randomly selected two workshop classes of preservice teachers to complete a brief fivepart Likert survey and extended written responses. Incomplete survey responses were deleted; hence there were 48 second-year preservice teachers (19\% male, $81 \%$ female), who were of varying ages, that is: $54 \%<21$ years of age, $8 \%$ between $22-29$ years of age, $38 \%>30$ years of age. Their secondary high school science studies were also varied with $42 \%$ completing biology, $2 \%$ physics, $21 \%$ multi-strand and $35 \%$ who had no science high school completion. When asked if they thought they would teaching primary science when entering the Bachelor of Education (BEd) degree $92 \%$ had understood this to be a requirement while $8 \%$ had not considered teaching primary science as part of the general BEddegree. The survey contained six statements with a five-part Likert scale, based on teaching primary science, and extended written responses that focused on their self-reported learning achievements as a result of the peer teaching lessons. Quantitative data were entered into SPSS to generate descriptive statistics (percentages, mean scores, and standard deviations) for analysis. The extended written responses were collated into themes as they emerged (Creswell, 2012). The first researcher (Hudson) observed all co-teaching primary science lessons $(n=24)$ over the semester period and used a laptop to take notes on the preservice teachers' presentations. The survey responses, written responses and observations with notes were used to triangulate data (Creswell, 2012).

\section{Results and Discussion}

Percentages from the Likert scale showed that one student only disagreed that her peer lesson presentation helped her with knowledge for teaching science. There were up to a quarter of 
the students who claimed they were unsure whether the peer lesson presentation helped them to demonstrate the knowledge for teaching science (though no one had a strongly disagree response on any item). Nevertheless, the majority were in agreement (agree and strongly agree) that the peer lesson presentations assisted them to learn about teaching science.Standard deviations $(S D)$ were low, indicating minimal variation in responses, and mean scores were in the upper end (range 3.93-4.65, Table 1). In percentage terms, out of 48 surveyed participants, $98 \%$ agreed or strongly agreed that the lesson presentation made them recognise the importance of teaching primary science with $94 \%$ indicating they learn to teach science by presenting to peers and $91 \%$ claimed they had developed a positive attitude for teaching primary science as a result of the experience (Table 1).

Table 1: Mean, standard deviation and percentages on teaching science

\begin{tabular}{lllllll}
\hline & Mean & SD & D & U & A & SA \\
\hline Teaching primary science is important & 4.35 & 0.55 & 0 & 2 & 31 & 67 \\
Learn to teach science & 4.65 & 0.60 & 0 & 6 & 52 & 42 \\
Enthusiastic for teaching science & 4.22 & 0.63 & 0 & 11 & 56 & 33 \\
Knowledge for teaching science & 3.97 & 0.62 & 2 & 25 & 65 & 8 \\
Positive attitude for teaching science & 4.25 & 0.60 & 0 & 9 & 58 & 33 \\
Cater for students needs science & 3.93 & 0.63 & 0 & 23 & 60 & 17 \\
\hline
\end{tabular}

These preservice teachers considered their achievements as a result of teaching a primary science lesson to their peers with some writing more than one achievement.Their comments about learning achievementswere collated into these broad themes: lesson planning, preparation, and implementation $(n=14)$, content knowledge (11), teaching strategies (6), confidence to teach (5), questioning skills (4), grade appropriateness (4), time management (3), critical observation of peers (3), reflection in practice (2), professionalism (2), connecting science to other subjects (2), receiving peer feedback (2), and development of vocal skills (2). There were various single comments that could not be collated into themes and were omitted from this analysis. The following presents and analyses data around these themes.

\section{Planning, preparation, implementation and confidence}

The peer teaching episodes provided opportunities for learning about planning and for learning about authentic preparation: "I really liked being prepared and practising the lesson and what I was going to say" (Participant 5). Indeed, these preservice teachers could self allocate negotiated times to prepare and practice their presentation in a vacant classroom up to a week before their actual lesson presentation. Observations indicated that the uptake of this voluntary allocation was significant. Further observations of preservice teachers rehearsing their co-teaching presentation also showed that preservice teachers built confidence for presenting in a co-teaching situation, particularly with the learning around available audio-visual equipment and information communication technologies (ICT). The connection between planning, preparation and confidence to teach was made very clear as a result of co-teaching to peers:

We were very well prepared, as we had started planning early and talked to people about the plan we made adjustments, and arranged and tested all equipment I felt confident and calm doing the lesson, because of planning, testing and practice. I understood the content and the expected outcome" (Participant 4).

Bandura (1986) claims self efficacy (belief in one's ability to accomplish a task) is related to confidence and can affect motivation and learning experiences. He also highlights vicarious and mastery experiences as approaches for developing self efficacy. In this study, the vicarious experiences appeared through pseudo primary student involvement and mastery 
experiences were being developed through first-hand involvement of co-teaching to peers.According to participants, this learning as pseudo primary students allowed them "to see other [co-teaching] ideas and generate my own from experiencing peers' lessons" (Participant 40).

All preservice teachers acknowledged their learning of primary science teaching as a result of co-teaching and participating in the science lessons. Many noted the experiences demonstrated the importance of students constructing knowledge, "To realise how important it is for students to construct their own knowledge by themselves through participating in activities and finding the lesson interesting.The importance of creating rich learning experiences" (Participant 1). The supportive environment with peers tended to allay concerns about teaching to some degree. Participant 6 claimed that the co-teaching to peers was "team building between the whole class (including teachers) because we are all stressed about it, we are all in the same situation" (parenthesis in original). The preservice teachers considered that participating in the co-teaching as both teachers and learners provided insights about planning, preparation and implementation, and the complexities of teaching: "learn new strategies of how to manage a classroom, how difficult teaching is and how complex it is" (Participant 4). The theory-practice connection also became apparent: "Seeing so many educational theories (that we have read and agonised over) put into practice was such a learning experience (Participant 17).

Planning and implementing lessons provided connections between planning a sound lesson structure and consistency of approaches, as some participants acknowledged: "the detail required to plan an effective and enjoyable lesson" (Participant 39) and "the way you structure and teach the lesson is just as important" (Participant 40) but also "how important it is to stick to an approach to make it effective" (Participant 38). As second-year preservice teachers, there was a realisation that planning and preparation were linchpins for teaching, which required knowledge of teaching approaches and strategies and trialling such approaches necessitates perseverance, especially as a new approach may require multiple trials before mastery. Yet, the complexities of teaching appeared more evident to the participants as they progressed through the co-teaching presentations.

The peer teaching episodes were established as a practical measure to increase their pedagogical knowledge, content knowledge and confidence for teaching primary science, which was demonstrated from researcher observations and within participant comments: "being confident about explaining scientific concepts" (Participant 18) and "I managed to speak confidently to this class, which I have struggled with before" (Participant 29). Peer supportiveness and presentations were claimed to instil more confidence in the preservice teachers: "My peers were super supportive and enjoyed my lesson" (Participant 24) that helped them to gain confidence for teaching primary science: "Successfully completing my science lesson to a reasonable standard and obtaining a better understanding about strategies to teach primary science. It was helpful listening to and being involved in lessons created by my peers" (Participant 41).Presenting to peers was recognised as a learning opportunity for understanding how to plan and implement primary science lessons, for instance, "being able to learn from peers and have a deeper understanding of primary science units" (Participant 46), and

This subject really gave us a little more insight into teaching a particular lesson. Even though it was to our peers it gave us the opportunity of presenting in front of an audience while teaching. Learnt how to really provide higher order thinking amongst the class. Learnt ways to address open discussions amongst peers and students. (Participant 47) 


\section{Science content knowledge}

Science content knowledge appeared as a significant theme, with 11 preservice teachers in this study claiming the peer teaching episodes assisted in their learning of content knowledge in two ways: planning and teaching, and participation in peers' lessons. Comments such as "I learnt so much about biology by planning this lesson and I enjoyed teaching it" (Participant 3 ) and "learning actual science content in an engaging way that I will remember for my future students" (Participant 15) demonstrated the self-reported impact peer teaching had on their learning of science content knowledge. Participation as a class member in the peer teaching assisted in bridging the content knowledge gap, for example, "I wasn't familiar with any of the science content yet throughout [the peer teaching]I've learnt a lot and started enjoying science" (Participant 10). Important to their learning was the recognition that content had to be "relevant" and preservice teachers needed to have an "understanding what a key science concept is" (Participant 8).

Within their responses, there was concern that they had to know all the answers in science, for instance: "Not being able to have answers for questions" (Participant 4) and "not being able to answer a question asked by a student or not being able to get around it without looking silly" (Participant 9). This suggested they had learnt about the importance of teacher preparedness and that the teacher must obtain "correct facts - so students do not learn incorrect information" (Participant 30) and "make sure that I have the correct information to give to students as I don't want to misinform them" (Participant 20). Notably, they had learnt that science knowledge changes continuously, "The ever changing nature of science. I am concerned about teaching a lesson that has been superseded and updated" (Participant 17); thus there was learning about the currency of content knowledge for the classroom, "making sure I teach the most recent information" (Participant 19). Although they had learnt about the need to have "correct knowledge and understanding to successfully teach and apply to primary science" (Participant 29), there was also recognition that the teacher must be an upto-date researcher of content knowledge to assist students more effectively, for example: "I'm worried I don't know enough about the subject matter to be able to teach it confidently, but I know I will be able to find lots of information from library and internet resources" (Participant 15), particularly "because science is factual yet changing" (Participant 21). However, the fear of not knowing the answers to questions can be as a result of primary students' questions going beyond the initial content preparation for the teacher, which requires further research as suggested in Participant 1's response: "You don't have to have all the answers to teach science.Science can be fun and interesting, you just have to explore it and find a way for yourself and your students to make a connection to the content/process". There was further learning that teachers "need to invest time, you can't just 'do' science for half an hour" (Participant 2). Observation of preservice teachers preparing themselves by practising their co-teaching lessons indicated that investing in learning about science content prior to teaching tended to establish a foundation for confidence building.

Even though there was concern about how much content knowledge was required for teaching science, the majority of participants explained in various words that content knowledge was achievable and essential for teaching, for example, "You have to really know your stuff, and that science is not scary at all" (Participant 16). There were points made about meaningful science in contrast to the transmission of facts, as noted in these two responses: "Scientific concepts can be presented in many practical hands-on ways.Science is about discovery and understanding not just the absorption of facts" (Participant 7) and that science teaching "doesn't appear as a whole bunch of facts - it needs to have real life meanings and applications" (Participant 16). Abruscato (2004) follows in the footsteps of Dewey's 
discovery learning and emphasises that students learn more effectively and timely through a process of guided discovery. These co-teaching participants were also guided in their discovery of primary science teaching through hands-on experiences and seemed to understand the necessity to be prepared for teaching the content before entering the classroom and "the science content and information can be gained through different methods, not only from textbooks (Participant 3). Similarly,

If you don't do very intense background research the lesson doesn't work, as students don't know what they are meant to learn/do. Therefore you'd have to go back over the topic and try to change students' conceptions that they developed in the "bad lesson" - this just confuses students. (Participant 5)

These responses suggested that it may not necessarily require preservice teachers to collect and retain copious amounts of content knowledge but rather be content prepared for the next science lesson, especially as content knowledge changes with new scientific discoveries and primary teachers generally do not teach the same science lesson within the same school year.

Participation as pseudo-school students helped these preservice teachers to develop their science content knowledge: "Through seeing lots of science lessons I have broadened my knowledge of the types of things I can teach in science" (Participant 8) and to "broaden my views on "what is science"" (Participant 14). Selecting content for specific differentiation of learning (i.e., addressing students' learning needs) was not mentioned by these second-year preservice teachers, which may well indicate their stage of development. However, some mentioned the need for connecting science content tograde and age appropriateness, for example: "The content and relevance of the topic in relation to the year level, and the fact that it was engaging and interesting to the class" (Participant 48) and "getting a greater understanding of what achievement levels are expected for different year levels - learning what is age appropriate" (Participant 25). Despite the peer presentations not being a "real" primary classroom with students of those age groups, the peer teaching was noted as way to "create a successful and plausible science lesson that could be used in a real classroom" (Participant 15).It was demonstrated through their comments and observations of teaching practices that learning to teach primary science in the university setting needed to be plausible and, indeed, applicable to the primary science classroom.

\section{Developing questioning strategies}

Several participants mentioned keeping science simple and fun to engage students with other important actions: "Questioning is important" (Participant 26) and "creating a simple hypothesis, and re-capping, is important" (Participant 31). From observations, participants articulated diagnostic questioning (i.e., questions used to elicit students' prior knowledge) and askedhigher-order thinking questioning to activate students' construction of science knowledge, which was further recorded in their written responses, for instance: "The use of questioning was a powerful tool to elicit prior knowledge. The use of questioning allowed students to construct their knowledge in the social setting" (Participant 6). Hypothesising and devising questions for investigation was noted as a successful science learning strategy: "Students investigating own questions keeps them engaged and really thinking" (Participant 5). Apart from learning about "how to do up a lesson plan, different strands in science, and lots of activities to implement into the classroom" (Participant 25), many preservice teachers such as Participant 32 emphasised that "everything needs to have a purpose - activities should not be time fillers, they should have an underlying concept.There is extensive reasoning/concepts/planning behind every single lesson". Purposeful learning was a main theme that threaded most comments with strong connections to drawing upon the national "syllabus and the source book guidelines" (Participant 37).Learning about the complexities of 
teaching emerged through involvement as pseudo students and co-teachers. Participants commented on refined questioning techniques guided by key science concepts linked to the national curriculum (e.g., ACARA, 2012).

\section{Curricula integration and science learning}

This particular university coursework provided the first practical application of curricula integration in their second year of university study, where the preservice teachers were encouraged to utilise other key learning areas (KLAs) to help facilitate the learning of science concepts, as shown in Participant 17's comment: "understanding that a science lesson has science knowledge/content, but can be presented in conjunction with another KLA - eg: drama". The usefulness of curricula integration for learning science was recognised by others, to illustrate: "I have learnt how to integrate other subjects in science and this will be very useful when I'm a teacher" (Participant 48), "that science can be used with any other subjects, you can combine" (Participant 6), and "that primary science is so easily and effectively integrated into other KLAs" (Participant 36). From observing the 24 co-teaching lesson presentations, more than half demonstrated strong links with other KLAs to capitalise on the learning of science concepts.

Integrating the arts features in the participants' practices and responses, for instance, curricula integration of drama in the form of role playing was considered as a valuable teaching strategy "because you are totally involved and take part 'as an ant'. Different activities allow people to show their different potentials e.g. being good at drama" and "role play to understand the learning as well as building a set of lungs". Observation of co-teaching also highlighted art, craft, music and multi-media as ways to communicate science content knowledge. Although some participants focused on content knowledge as the reason for the lesson being memorable, integrating subjects was emphasised as a memorable method for learning: "Talking about features and adaptations of animals in different environments then creating our own", and "role playing - oxygen coming in, $\mathrm{CO}_{2}$ coming out.People played $\mathrm{O}_{2}$ or $\mathrm{CO}_{2}$ molecules". Indeed, the artswere noted as an engaging way to get across the science ideas, such as "having different activities for each group and incorporating other subjects integration and dressing up as ants". Hudson's (2012) model of curricula integration demonstrates that other subjects can be used as tools for investigating science concepts, which relies on a teacher's pedagogical knowledge and creativity insights.Observation of coteaching showed that many participants employed creative strategies that drew upon other curriculum areas for the sole purpose of enhancing science understandings.

\section{Learning from peers' co-teaching}

Without selecting or referring to their own presentations, these preservice teachers were asked about primary science lessons that stood out during their peers' presentations. This made them focus on their most memorable science lessons, which were spread across particulartopics such as: miniworlds $(n=12)$, erosion (8), respiratory system (8), chemical reactions (8), animals (6), human skeleton (3), solids and liquids (3) andsingle responses (e.g., testing for acidity, paper making). Although the first five topics showed six or more in agreement with these being memorable, the spread indicated that some topics were enjoyed more so by different participants, which may be indicative of their varied needs and interests. They were asked reasons for their choices andthe key features of thememorable lesson they selected individually. Most participants commented on the presenters' enthusiasm (teacher's affective domain), the practical hands-on nature of the activity (kinaesthetic learning), and the overall structure of the lesson (planning and implementation). 
These preservice teachers were asked to identify key features of thismemorable co-teaching lesson that they experienced as substitute primary students. There were key features that stood out for these participants as recipients of their peers' teaching. Many comments focused on the classroom management, hands-on lesson activities, and the technology, as represented by Participant 13, "praise and reward, PowerPoint slides and group activities" and Participant 17, "engaging, informative, fun, constructivist, hands-on". The practicalities of the science activities were recognised by peers, for example, "designing a waterway to prevent erosion and using the information given to construct it/build it" (Participant 34). Hands-on experiences were emphasised as a key feature to maintain interest and stimulate scientific thinking, "The discussion and activities encouraged critical thought and assisted in engaging my interest (Participant 39). In addition, activities that centred on science education for sustainable living (SESL, see Hudson, 2007c) was highlighted as key featuresof peer lesson presentations: "connection to sustainable living" (Participant 28) and "sustainable resources environmentally friendly alternatives, paper recycling" (Participant 30).

The second-year preservice teachers identified effective strategies observed during their peers' lesson presentation, which can be classified generally at the macro and micro levels of teaching.At the macro level, and as a result of their engagement in lecture and tutorial materials, participants identifiedbroad teaching approaches employed during the lesson presentations, to illustrate: "role play teaching style, constructivism approach", "guided discovery, transmission, process skills", "shared instruction between teachers - both explained concepts, constructivism, guided discovery", and "POE [Predict, Observe, Explain] and Bloom's Taxonomy" were recognised as teaching approaches. At the macro level there was recognition of lessons that "catered for a wide variety of learning styles". Participants identified effective strategies at the micro level, particularly classroom management techniques: "good classroom management, loud clear voice", "classroom management was excellent, group work was present", and "clear classroom management strategies".Furthermore, at the micro level, the use of questioning skills that assisted in "higher order thinking" and hands-on activities that were "student centred, hands-on learning, predicting, allowing students to try different things to make a different reaction". Indeed, most comments focused on pedagogical knowledge that promoted student engagement, including the use of resources such as "technologies to engage students" and having a "variety of fun and engaging activities, videos etc". The preservice teachers were encouraged within the coursework assessment criteria to select varied teaching strategies; consequently some drew upon other BEdcoursework ideas such as drama to engage students:

Class role play about how we breathe and some people were the nose and so on then we all as a class were the oxygen walking the cycle. We also did an experiment where we made a set of lungs from balloons.(Participant 27)

Overall, teaching science was acknowledged as a creative process with "many ways to teach science, not just one way.Each topic can be taught in a very creative and interesting way. This varies for different people though" (Participant 4). These participants outlined that they had learnt from observing and participating in their peers' co-teaching of primary science lessons. They evaluated the effectiveness of their lessons by drawing on their own experiences, tutor's feedback, and written feedback from peers. This evaluation was another level for copresenters to reflect on practices towards refining their own teaching about what works and what does not work. The creative delivery of lessons were observed and experienced by peers to instil a sense of how particular lessons can have an impact on the learner. Indeed, Davis and Smithey (2009) claim that, "Beginning elementary teachers thus require many areas of mastery, yet generally lack both sufficient coursework and experience that would contribute to their knowledge base for helping children" (p. 2). The peer presentations in this study acted 
as pseudo primary teaching experiences where co-teachers analysed and collaboratedoneffective pedagogical knowledge practices and determined appropriate content knowledge to be taught.

\section{Conclusion}

This study aimed to investigate preservice teachers' self-reported learning as a result of coteaching experiences to peers. The co-teaching to peers provided a way to develop teaching practices in a safe and supportive university environment, particularly as they were in their second year of a four-year degree and this was their first opportunity to have practical teaching experiences. Teaching is complex and, with the range of primary student abilities and behaviours, this study showed that co-teaching in the university setting scaffolded the development of fundamental teaching practices. These second-year preservice teachers selfreported learning on how to teach included planning and implementation with further learning about the essential nature of preparing for science content knowledge, selection of appropriate teaching strategies and employing insightful questioning techniques, including the use of open and closed questions, and lower- and higher-order thinking questions.

Learningteaching skills and practices before entering authentic primary classrooms can allow preservice teachers to focus on the fundamentals of teaching before the somewhat unpredictable elements (e.g., student behaviour) of a real primary classroom. The co-teaching was emphasised as confidence building and that theseplausible science lessons"could be used in a real classroom". According to participants' self-reported learning, this co-teaching arrangement provided opportunities to develop content knowledge and pedagogical knowledge, which extended to viewpoints about how to construct an effective primary science lesson. Such viewpoints included curricula integration, especially through the arts (drama, art, media) that may assist students for developing science conceptual understandings. However, criteria in university assessments need to outline explicitly desirable teaching practices for university students to follow.

Universities seek ways to connect theory with practice (praxis) for preservice teachers, and teaching such connections generally requires preservice teachers entering primary classrooms. Indeed, preservice teachers need to develop confidence and skills before entering real school, thus opportunities to teach to their peers within the university setting can facilitate fundamental skills for teaching at very early stages of development. The learning reportedly occurred through co-teaching and as recipients of the co-teaching arrangements, and the impact on this learning for teaching primary science was clearly evident in their responses. Co-teaching primary science to peers scaffolds the development of teaching skills and practices through dual roles as teachers and student recipients of co-teaching practices. In addition, constructive feedback to co-teachers allowed for cognitive analysis of effective teaching, and reflection in and on practices further scaffolded their development. Evaluatinguniversity coursework in teacher education to include opportunities for scaffolding preservice teachers' skill development,beginning with co-teaching arrangements during early stages to solo teaching arrangements as they progress through their coursework, may produce a more prepared cohort of future teachers, not just in science buy across all primary education subjects. More research is needed to explore co-teaching in other subject areas and to further identify the complexities of teaching that could be unpacked and embedded, practically, in university coursework.

Acknowledgement: The clerical assistance from Beryl Hudsonwas very much appreciated. 


\section{References}

Abruscato, J. (2004). Teaching children science: A discoveryapproach. NY: Allyn\& Bacon.

Ackley, B., \& Gall, M. (1992, April). Skills, strategies and outcomes of successful mentor teachers. Paper presented at the annual meeting of the American Educational Research Association, San Francisco, CA.

American Association for the Advancement of Science. (1990). Science for all Americans: A project 2061 report on literacy goals in science, mathematics and technology. Washington, DC: Author.

Bandura, A. (1986). Social foundations of thought and action: A social cognitive theory. Englewood Cliffs, NJ: Prentice Hall.

Bradfield, K., \& Hudson, P. (2012, August). Examining teaching strategies within preservice teachers' practicum experiences. Paper presented at the $19^{\text {th }}$ International Conference on Learning, London, England.

Briscoe, C., \& Peters, J. (1997). Teacher collaboration across and within schools: Supporting individual change in elementary science teaching. Science Teacher Education, 81(1), 51-64.

Buczynski, S., \& Hansen, C. B. (2010). Impact of professional development on teacher practice: Uncovering connections. Teaching and Teacher Education, 26(3), 599-607.

Burn, K. (2007). Professional knowledge and identity in a contested discipline: Challenges for student teachers and teacher educators. Oxford Review of Education, 33(4), 445467.

Cleaves, A., \&Toplis, R. (2008). Pre-service science teachers and ICT: Communities of practice? Research in Science \& Technological Education, 26(2), 203-213.

Cochran-Smith, M., \&Zeichner, K. (2005) (Eds). Studying teacher education. New York: Routledge.

Corey, D. L., Phelps, G., Ball, D. L., Demonte, J., \&Harrison, D. (2012). Educational Evaluation and Policy Analysis, 34(2), 146-163.

Creswell, J. W. (2012). Educational research: Planning, conducting, and evaluating quantitative and qualitative research $\left(4^{\text {th }}\right.$ Edn. $)$. Upper Saddle River, NJ: Pearson Education Inc.

Davis, E. A., \& Smithey, J. (2009). Beginning teachers moving toward effective elementary science teaching. Science Education, 93(4), 745-770.

Davis, E. A., Petish, D., \& Smithey, J. (2006). Challenges new science teachers face. Review of Educational Research, 76(4), 607-651.

Feiman-Nemser, S., \& Parker, M. B. (1992). Mentoring in context: A comparison of two U.S. programs for beginning teachers. NCRTL Special Report. East Lansing, MI: National Center for Research on Teacher Learning.

Gencer, A. S., \&Cakiroglu, J. (2007). Turkish preservice science teachers' efficacy beliefs regarding science teaching and their beliefs about classroom management. Teaching and Teacher Education, 23(5), 664-675.

Goodrum, D., Hackling, M., \& Rennie, L. (2001). The status and quality of teaching and learning in Australian schools. Canberra, Australia: Department of Education, Training and Youth Affairs.

Harris, D. N., \& Sass, T. R. (2009). What makes for a good teacher and who can tell: National Center for Analysis of Longitudinal Data in Education Research.

Hudson, P. (2004). Toward identifying pedagogical knowledge for mentoring in primary science teaching. Journal of Science Education and Technology, 13(2), 215-225.

Hudson, P. (2007a, September). Analysing assessment rubrics designed by preservice primary science teachers. British Educational Research Association (BERA) Annual Conference. 
Hudson, Nykvist, \& Mukherjee (2016). Education Reform Journal, 2016, 1(2), 34-48

London, England: British Education Index. (Refereed papers published online.) Available from: http://www.leeds.ac.uk/educol/documents/165823.doc 14

Hudson, P. (2007b). High-impact teaching for science. Teaching Science, 53(4), 18-22.

Hudson, P. (2007c). Middle school science education for sustainable living. Middle School Journal, 38(4), 43-47.

Hudson, P. (2012). A model for curricula integration using the Australian Curriculum. Teaching Science, 58(3), 40-45.

Jeanpierre, B. (2007). Becoming an urban school middle-level science teacher. Journal of Elementary Science Education, 19(1), 45-55.

Jonson, K. F. (2002). Being an effective mentor: How to help beginning teachers succeed. Thousand Oaks, CA: Corwin Press.

Kohler, F., Henning, J. E., \&Usma-Wilches, J. (2008). Preparing preservice teachers to make instructional decisions: An examination of data from the teacher work sample. Teaching and Teacher Education, 24(8), 2108-2117.

Korthagen, F. A. J. (2001). Linking practice and theory: The pedagogy of realistic teacher education. Mahwah, N.J.: L. Erlbaum Associates.

Lappan, G., \& Briars, D. (1995). How should mathematics be taught? In National Research Council. National science education standards. Washington, DC: National Academy Press.

Lunn, S., \& Solomon, J. (2000). Primary teachers' thinking about the English national curriculum for science: Autobiographies, warrants, and autonomy. Journal of Research in Science Teaching, 37(10), 1043-1056.

Maag, J. (2008). Rational-emotive therapy to help teachers control their emotions and behavior when dealing with disagreeable students. Intervention in School and Clinic, $44,52-57$.

Masters, G. N. (2009). Improving literacy, numeracy and science learning: Preliminary advice. Assessment and reporting projects. Retrieved from http://research.acer.edu.au/ar misc/4

McDonald, J. T., \& Dominguez, L. A. (2010). Professional Preparation for Science Teachers in Environmental Education. In A. M. Bodzin, B. S. Klein \& S. Weaver (Eds.), The Inclusion of Environmental Education in Science Teacher Education (pp. 17-30): Springer Netherlands.

McKinney, S. E., Campbell-Whately, G. D., \& Kea, C. D. (2005). Managing student behavior in urban classrooms: The role of teacher abc assessments. Clearing House: A Journal of Educational Strategies, Issues and Ideas, 79(1), 16-20.

O'Brien, P., \& Goddard, R. (2006). Beginning teachers: Easing the transition to the classroom. Australian Educational Leader, 28(1), 28-31.

Ozogul, G., Olina, Z., \& Sullivan, H. (2008). Teacher, self and peer evaluation of lesson plans written by preservice teachers. Educational Technology Research and Development, 56(2), 181-201.

Pantic, N., \&Wubbels, T. (2010). Teacher competencies as a basis for teacher education Views of Serbian teachers and teacher educators. Teaching and Teacher Education, 26(3), 694-703.

Parr, J. M., \&Limbrick, L. (2010). Contextualising practice: Hallmarks of effective teachers of writing. Teaching and Teacher Education, 26(3), 583-590.

Putman, S. M. (2009). Grappling with classroom management: The orientations of preservice teachers and impact of student teaching. The Teacher Educator, 44(4), 232-247.

Randler, C., \&Frech, D. (2009). Young people's time-of-day preferences affect their school performance. Journal of Youth Studies, 12(6), 653-667. 
Rosean, C., \& Lindquist, B. (1992). Collaborative teaching and research: Asking 'What does it mean?' Elementary Subject Centre Series No.73. Michigan: Institute for Research on Teaching, MSU.

Rush, L. S., Blair, S. H., Chapman, D., Codner, A., \& Pearce, B. (2008). A new look at mentoring: Proud moments and pitfalls. Clearing House, 81(3), 128-132.

Santagata, R., Zannoni, C., \& Stigler, J. (2007). The role of lesson analysis in pre-service teacher education: an empirical investigation of teacher learning from a virtual videobased field experience. Journal of Mathematics Teacher Education, 10(2), 123-140.

Schön, D. (1987). Educating the reflective practitioner. San Francisco, CA: Jossey Bass.

Schwarz, C. (2009). Developing preservice elementary teachers' knowledge and practices through modeling-centered scientific inquiry. Science Education, 93(4), 720-744.

Shulman, L. (1986). Those who understand: Knowledge growth in teaching. Educational Researcher, 15(2), 4-14.

Tillema, H. H. (2009). Assessment for learning to teach: Appraisal of practice teaching lessons by mentors, supervisors, and student teachers. Journal of Teacher Education, 60(2), 155-167.

Williams, A. (1993). Teacher perceptions of the needs as mentors in the context of developing school-based initial teacher education. British Educational Research Journal, 19(4), 407-420.

Youens, B., \& McCarthy, S. (2007). Subject knowledge development by science student teachers: The role of university tutors and school-based subject mentors. Research in Science \& Technological Education, 25(3), 293-306. 